\title{
Replacement of Analog Automatic Voltage Regulator using Digital Technology
}

\author{
Ersalina Werda Mukti, Sulistyo Wijanarko, Anwar Muqorobin \\ Research Center of Electrical Power and Mechatronic (P2Telimek), Indonesian Institute of Sciences (LIPI), \\ Indonesia
}

\section{Article Info \\ Article history: \\ Received Jul 12, 2015 \\ Revised Oct 25, 2015 \\ Accepted Nov 16, 2015 \\ Keyword: \\ Analog AVR \\ Digital AVR \\ Embedded system \\ Synchronous generator}

\begin{abstract}
Before the 90's, many power plants in Indonesia were equipped with analog controllers and now those power plants are still in operation to produce electricity. One of those controller parts is Automatic Voltage Regulator (AVR). If a failure occurs in the AVR, the economic solution is by replacing the damaged electronic component with new component. However this method will not solve the problem if the components are not available in local market or become obsolete. Purchasing the new AVR that compatible with other controller parts cannot be done again because the analog controllers are no longer produced by the vendor. Furthermore, replacement of all the controllers with the current technology become expensive. According to this, an alternative solution is proposed in this paper by designing an AVR that compatible with other controller parts and considering the availability of the electronic components in local market. ATmega 8 microcontroller is used to implement a digital AVR and employing op amp based as its signal conditioning. The result shows that the digital AVR can reduce hardware size and power consumption. The digital AVR also meets the computation rate of the computation signal.
\end{abstract}

Copyright (C) 2016 Institute of Advanced Engineering and Science. All rights reserved.

\section{Corresponding Author:}

Ersalina Werda Mukti,

Research Center of Electrical Power and Mechatronic (P2Telimek),

Indonesian Institute of Sciences (LIPI), Indonesia

Email: ersa001@lipi.go.id

\section{INTRODUCTION}

Power plant should provide electricity that comply some standard specifications in terms of power, voltage, and frequency to meet the power system stability. In many power plants, electrical power is generated by synchronous generator. Excitation system is needed by synchronous generator to generate the output voltage. Figure 1 shows the excitation system of synchronous generator $[1,2]$ that consists of exciter, regulator, voltage sensor, load compensator, power system stabilizer, protection, and limiter. The exciter is used as DC voltage sources for field winding of synchronous generator and its value is controlled by the regulator. The regulator operates based on the reference voltage and the output feedback provided by voltage sensor, load compensator, protection and limiter, and power system stabilizer (PSS).

There are two operation modes of voltage regulator, i.e. manual and automatic. The automatic voltage controller is commonly known as Automatic Voltage Regulator (AVR). Until the end of 90’s, analog components dominate the manufacturing process of AVR. The first digital AVR was produced by Basler in 1991 [3]. However, the analog controllers are still widely used until now. During power plant operation, when failure occurs in the analog AVR, its maintenance process becomes difficult because the analog AVR is no longer produced by the manufacturer. Furthermore, replacing the overall components in the existing system is uneconomical solution. 


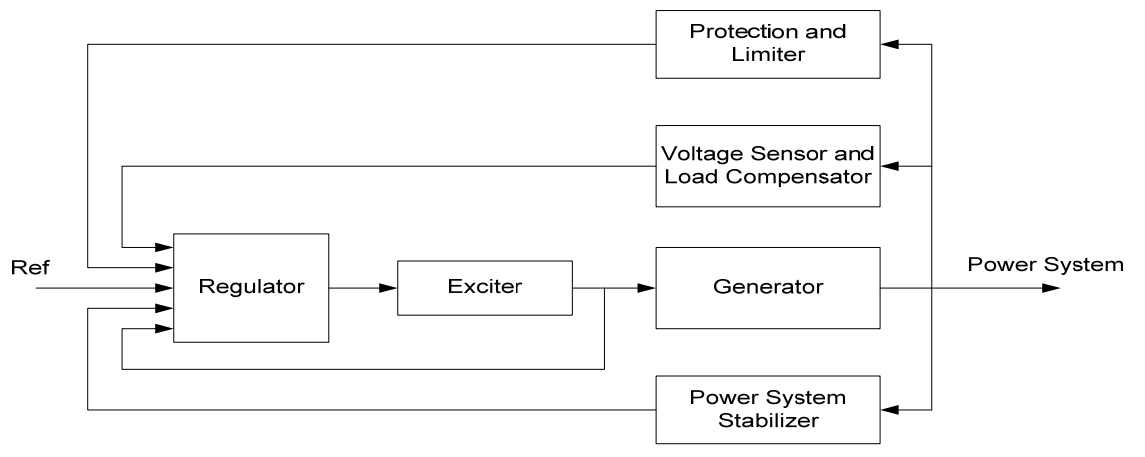

Figure 1. Excitation control system of synchronous generator

The analog AVR should be replaced as the alternative way to overcome the difficulty of its maintenance process. Some drawbacks of the analog system have driven research on the design of digital component-based AVR, i.e. higher power consumption and design complexity. This research is the continuation of the previous researches $[4,5]$ that built sub part of AVR, i.e. voltage setter 1 (VS1), thyristor trigger pulse monitor, and signal conditioning. Compared to the analog AVR, the digital AVR is easier in the tuning process [6] so that it accelerates the installation [7].

Several control techniques are applied in practical power system devices such as the digital AVR in order to obtain robust and high performance voltage controller in term of response time [8]. PID controllers with fixed and variable parameters are usually used in voltage control applications because they do not require exact or explicit system modeling. Fuzzy logic and neural network controllers [9, 10] can achieve good performance without requiring accurate model of the real system but the closed-loop stability is not ensured. Further studies has been implemented for tuning PID controller using pole placement and pole zero cancellation method [11] and artificial intelligent [12].

The implementation of digital technology using microcontroller in switching purposes has shown reliable and high precision of controlling duties. Accurate signal acquisition, high precision, and strong antiinterference capability of the thyristor trigger pulse and isolation of output can be achieved by combining microcontroller with specific synthetic trigger circuit of main circuit [13]. Microcontroller also provides a highly flexible, power efficiency, and cost effective solution to many embedded control applications [14, 15].

This paper proposes the design of digital AVR to be fit to other components in the excitation system. The method in designing digital AVR is discussed in Section 2 while the comparison between the digital AVR and the analog AVR will be discussed in Section 3. Then, Section 4 concludes the paper.

\section{RESEARCH METHOD}

In this research, the analog AVR that has been implemented in hydro power plant is first studied. Then, the digital AVR will be designed based on it. Some parts of the digital AVR will be retained analog to provide the signal conditioning function. Testing of the digital AVR will be done by using the generator and excitation modeling circuit to generate the generator output voltage.

\subsection{Analog AVR}

Figure 2 shows the analog AVR used in hydro power plant Wadas Lintang Banjarnegara Central Java Indonesia. The position of electronic components in excitation system is shown in Figure 3 [16]. The size of the analog AVR in the rack cabinets for each card is $35 \times 23.4 \mathrm{~cm}^{2}$. Figure 4 shows the block diagram of AVR. The analog AVR consists of eleven modules which are Voltage Detector (VD), Voltage Setter 1 (VS1), Voltage Setter 2 (VS2), Voltage Regulator (VR), Matching Amplifier (MA), Firing Angle Regulator (FAR), FAR Pulse Monitor (FARMON), VF Compensation (VFC), Line Charge Circuit (LCC), Field Current Limiting Circuit (FCLC), and Line Drop Compensation (LDC). Thyristor driver circuit and sensor are also needed.

The PI control is chosen in order to get instantaneous control action. The equation of PI control [17]:

$$
U(s)=K_{p}\left(1+\frac{1}{s T_{i}}\right) E(s)
$$


Where $U(s)=$ PI control's output, $E(s)=$ error of reference signal with feedback, $K_{p}=$ proportional constant, and $T_{i}=$ integral time (reset time). The analog AVR allows the constant tuning Kp ranging from 0 to 20 and Ti 0.1 to 2 seconds.

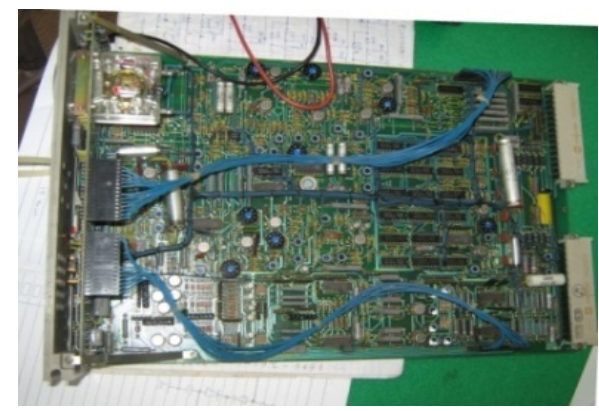

Figure 2. Analog AVR

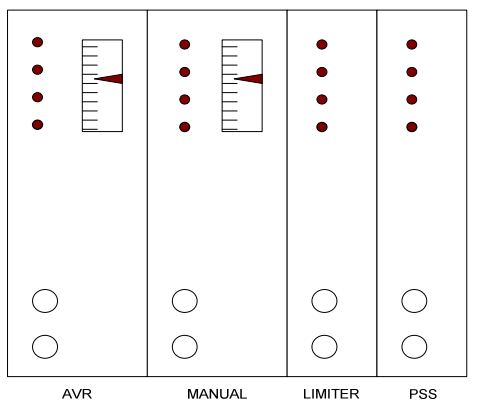

Figure 3. Position of electronic components in the excitation system

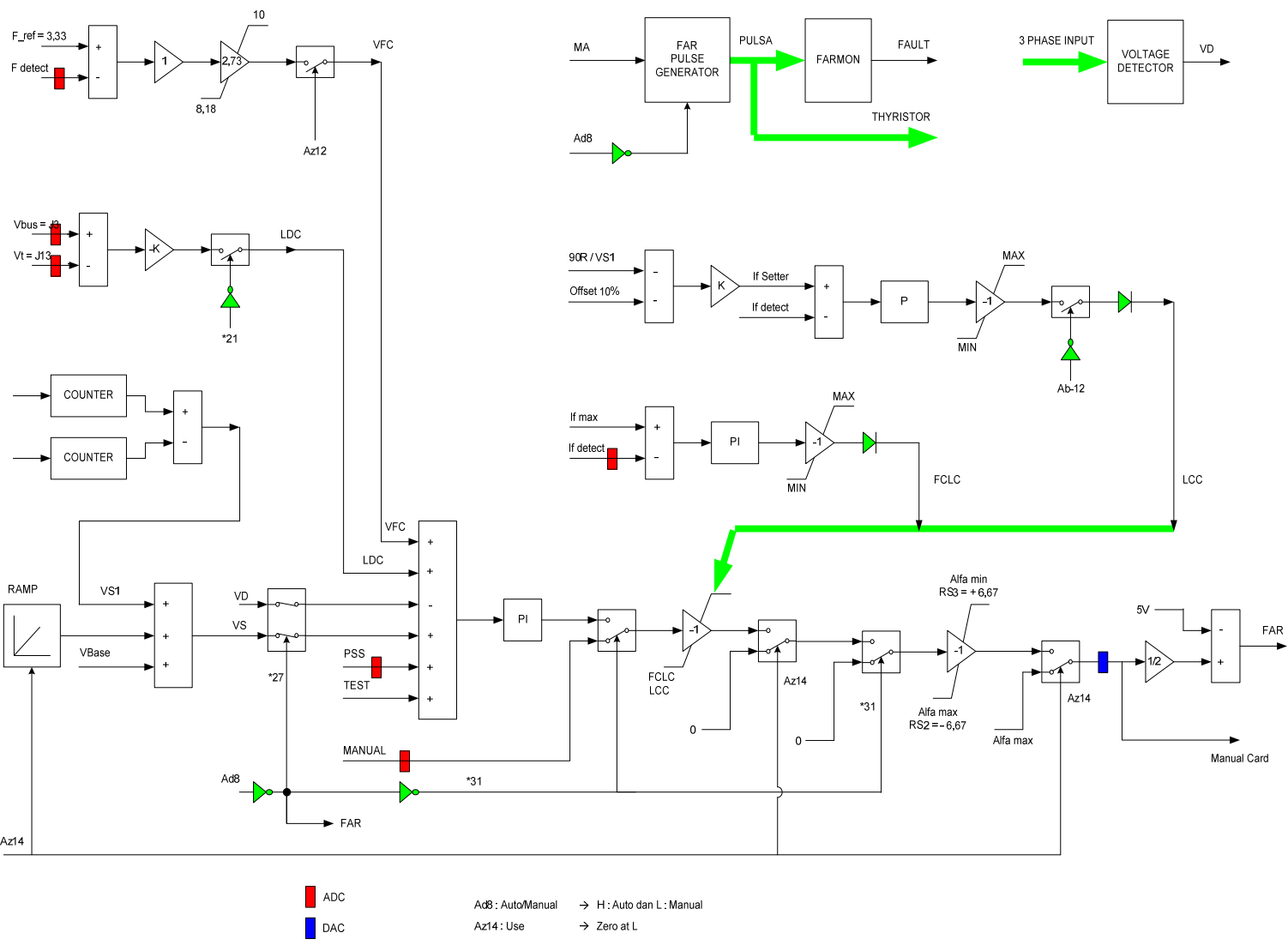

Figure 4. Block diagram of the analog AVR

Figure 5 shows the comparison between current and voltage reference of the analog AVR at the time activated together. The lowest reference will take over control action that is given to thyristor. The voltage reference will be added to the operator input. For current reference, minimum value is about $10 \%$ and the meeting point with voltage reference at point of $90 \%$. Thus, the amplification of current reference to the operator input is eight times. From the graph, ramp reference for voltage is not used if the current reference is used.

The analog signal inputs are sent to AVR from voltage sensor of generator terminal, infinite bus voltage, and field current that are rectified by the diode bridge. Reference in form of ramp function is used to 
avoid the high spike by using Voltage Setter 2 module. Field current control with maximum field current reference is used to avoid control action that causes field current exceeding its maximum value. The output is six voltage pulses sent from AVR to trigger the thyristor in form of static excitation.

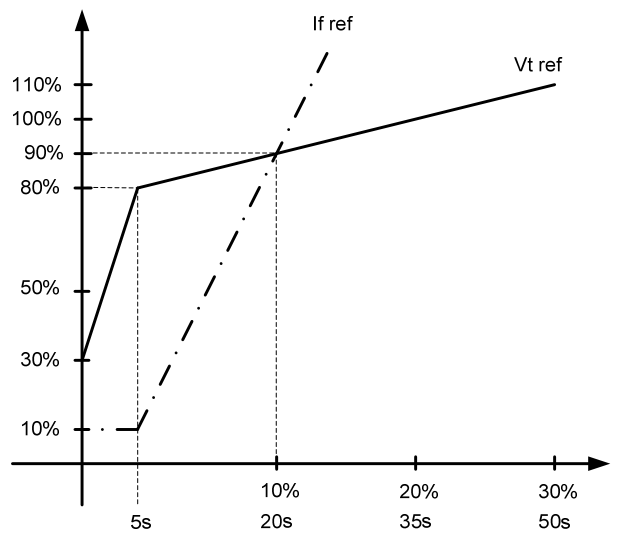

Figure 5. Comparison of voltage and current reference

\subsection{Digital AVR}

In the digital AVR design, the characteristics that must be complied in the embedded system are considered [18]. However, size, power consumption, and computation rate are the limitation for those characteristics. In order to comply those limitations, some parts of analog AVR are considered to be changed into digital in form of software whilst some parts are retained analog.

The first selected component to implement digital AVR is microcontroller because this component has small dimension, low cost, low power consumption rate, and easy to be programmed. The integration of single purpose processor like ADC and PWM makes the circuit become simpler. The previous researches showed that the use of ATmega8 microcontroller is to monitor the pulse and the voltage setter only needs $9.3 \%$ memory flash and $0.4 \%$ RAM. Therefore, it can be seen that the microcontroller capacity only be used in small capacity of its actual capacity.

The analog input in terms of generator voltage, infinite voltage bus, field current, frequency, PSS, and manual input, respectively, use ADC0 to ADC5 pins (23th to 28th pin) as shown in Figure 6. The logic input use PD0 to PD6 pins, whereas the logic output use PD7, PB0, and PB2 pins. PB1 pin is used to generate PWM signal that suits to the PI control output. The PI control output is compared to the triangle wave that has been synchronized to generate the PWM signal for triggering thyristor. The PWM signal is generated by the analog FAR circuit.

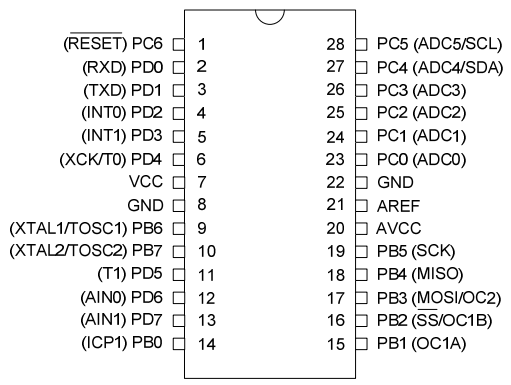

Figure 6. Pin configuration of microcontroller (ATmega 8)

ATmega 8 microcontroller [19] has three timers, Timer 0, Timer 1, and Timer 2. The used timer is Timer 1 to generate PWM signal and Timer 2 to generate interruption of control sampling time. Interruption from Timer 2 has higher prioritization than Timer 1. Half cycle of the $50 \mathrm{~Hz}$ AC generator frequency is 
selected for control sampling time that is $10 \mathrm{~ms}$ [20]. Timer 2 uses clocking frequency $62.500 \mathrm{kHz}$. It needs calculation until 625 to generate the interruption each $100 \mathrm{~Hz}$. If it is set 125 as maximum, the program will be operated after five times interruption.

In the analog AVR, VS1 module uses two counters 4 bit that counts up or down based on the pressed button by the operator. The VS1 signal will be updated every $5.69 \mathrm{~Hz}$ because the maximum calculation is 8 bits and the increasing period from zero to $30 \%$ is 45 seconds. The counter output is converted into the analog signal by using 8 bits digital to analog converter (DAC). The updated frequency gives changing to the reference less smooth. Thus, the VS1 output needs to be filtered before be used by the VR module.

In the previous researches, VS1 was implemented with the sequencial program designed to run every $175.781 \mathrm{~ms}$. Timer 0 is used to generate the interruption so that the program is run in the prearranged time. Timer 0 is 8 bits timer and able to generate interruption when the calculation reaches the highest value. With the crystal frequency $12 \mathrm{MHz}$ and the clocking divider 1024, the interruption is generated every 21.845 ms. The program is run every 8 times interruption, hence the sampling time become $174.763 \mathrm{~ms}$. At the running condition, the program counts up and down generating the output in form of PWM. Contrary to the previous research, in this research, VS1 is not implemented into one processor with FARMON, but it is combined with modules. Thus, the VS1 signal is not updated every $175.781 \mathrm{~ms}$, but every $10 \mathrm{~ms}$. In every sampling process, the VS1 signal is added or subtracted by 0.0006 .

The output of three voltage sensors are sent to the diode bridge to generate the DC voltage. Voltage divider is used ranging from $0 \mathrm{~V}$ to $-10 \mathrm{~V}$ that represents the AC generator voltage ranging from $0 \%$ to $110 \%$. The used signal conditioning is shown by Figure 7 . The signal conditioning works as low pass filter with the cut off frequency $159 \mathrm{~Hz}$. The used filtered is the first order filter because it needs less component and the ripple with $300 \mathrm{~Hz}$ frequency from diode bridge is not passed by the generator. The filter gain is 1 so that the divider of sensor voltage is tuned to give the output ranging from $0 \mathrm{~V}$ to $-5 \mathrm{~V}$.

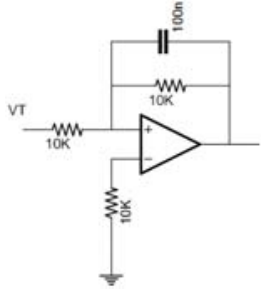

Figure 7. The signal conditioning for terminal voltage, infinite bus voltage, and field current

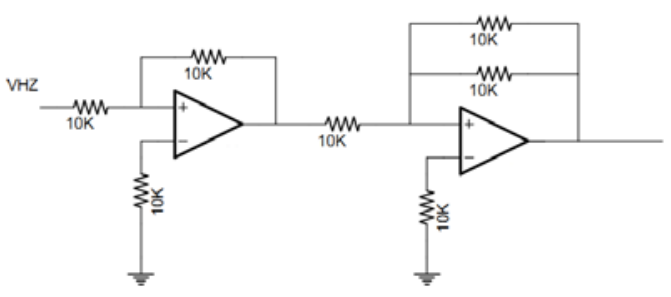

Figure 8. The signal conditioning for sensor frequency

The output of frequency sensor is ranging from $0 \mathrm{~V}$ to $10 \mathrm{~V}$. In order to fit the ADC microcontroller, it needs to be attenuated half time by using the signal conditioning in Figure 8. Low pass filter is not used in the signal conditioning for sensor frequency.

Signal conditioning for PSS and manual input are shown by Figure 9. This signal conditioning changes the input ranging from $-10 \mathrm{~V}$ to $+10 \mathrm{~V}$ into $0 \mathrm{~V}$ to $5 \mathrm{~V}$. The low pass filter is not used in order to not affect the signal processing result that is done by PSS and manual card. The PWM signal is transformed into the analog signal by using low pass filter. The second-order filter is used to eliminate the high frequency components from PWM.

The control signal is sent to microcontroller in form of PWM. By using the clocking frequency 16 $\mathrm{MHz}$ and fast PWM with peak 3FF in form of hexadecimal number or 1023 in form of decimal number, the PWM frequency becomes $15.625 \mathrm{kHz}$. The output of PWM is filtered by low pass filter shown by Figure 10 with cut off frequency $1592 \mathrm{~Hz}$ to get the analog voltage ranging from $-10 \mathrm{~V}$ to $+10 \mathrm{~V}$. 


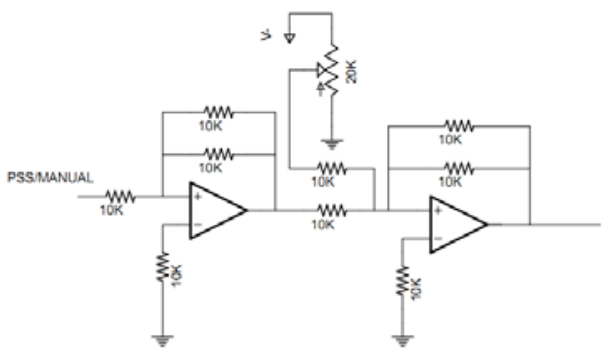

Figure 9. Signal conditioning for PSS and manual input

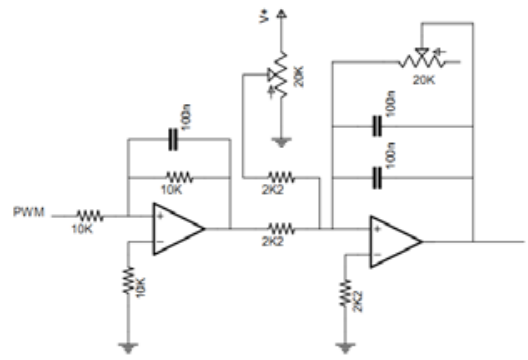

Figure 10. Filter for DAC

\section{RESULTS AND ANALYSIS}

In order to verify the proposed design, simulation has been proposed to comply the AVR design criteria. The experiment is done by simulating the generator terminal voltage generated by the synchronous generator and modeling the exciter circuit that are given as the following transfer function:

$$
G(s)=K_{s} \frac{1}{1+s T_{e}} \frac{1}{1+s T_{d o}^{\prime}}
$$

$K_{s}, T_{e}$, and $T_{d o}^{\prime}$, respectively, system gain, time constant of exciter, and time constant of generator. The used generator parameters in this simulation are $K_{s}=10, T_{e}=0.3, T_{d o}^{\prime}=3$. Synchronous generator and exciter using opamp-based analog circuit are used to test the PI controller. The exciter transfer function is built from capacitor $1 \mathrm{uF}$ and resistor $300 \mathrm{kOhm}$. Whereas the generator transfer function is built from capacitor $1 \mathrm{uF}$ and resistor $3 \mathrm{MOhm}$.

In the simulation, sine signal interferences are used to represent the ripples generated by the diode bridge of voltage sensor. The interference amplitude is 0.07 times of the output signal generator. The $300 \mathrm{~Hz}$ interference frequency is selected as the largest frequency in the simulation. Therefore, the simulation is iterated with sampling frequency $100 \mathrm{kHz}$ which higher than 100 times of interference frequency.

The simulation result of analog AVR using $\mathrm{Kp}=1$ and $\mathrm{Ti}=2$ seconds is shown in Figure 11. It can be seen that the use of ramp function reference can reduce the high spike. The changing of reference from $80 \%$ to $100 \%$ is shown in Figure 12. There is no interference frequency $300 \mathrm{~Hz}$ in the generator output because the signal is filtered by the exciter transfer function with cut off frequency $0.53 \mathrm{~Hz}$ and the generator with cut off frequency $0.053 \mathrm{~Hz}$.

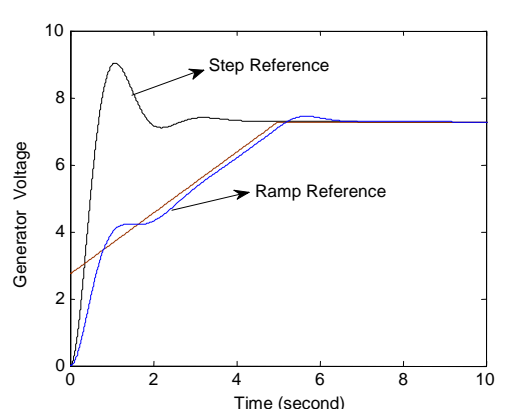

Figure 11. PI control response

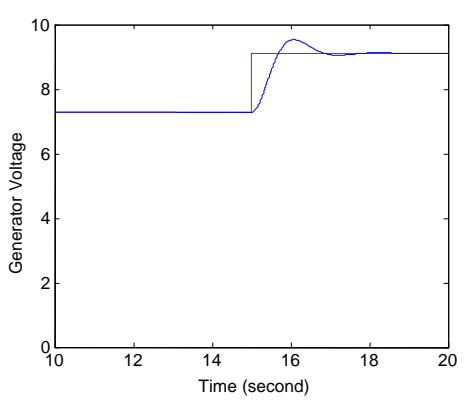

Figure 12. Step response with PI control

The designed of digital AVR is shown by Figure 13. The PCB's size is $11.3 \times 7.3 \mathrm{~cm}^{2}$. The available space for digital components is $21.8 \times 16.1 \mathrm{~cm}^{2}$. The placement of digital AVR into analog AVR is shown in Figure 14. It is shown that the digital AVR has smaller dimension than the analog components that its function has been replaced. Comparison of the replaced analog AVR's components with digital components is shown in Table 1. It is shown that the components that is used in the digital AVR are less than the analog. From this component list, the power consumption is able to be estimated by considering op amp and microcontroller. The op amp usually requires maximum current $6.6 \mathrm{~mA}$ and supply voltage $5 \mathrm{~V}$ so that 
$33 \mathrm{~mW}$ power is consumed. Microcontroller requires maximum current $12 \mathrm{~mA}$ and supply voltage $5 \mathrm{~V}$ so that $60 \mathrm{~mW}$ power is consumed. The analog AVR consumes about $450 \mathrm{~mW}$ from 14 op amps while the digital AVR consumes about $260 \mathrm{~mW}$ from 6 op amps and single microcontroller. Therefore, the designed digital AVR needs less power than the analog AVR. FAR circuit remains analog due to the limited pins of ATmega 8 microcontroller.

The output of DAC circuit is shown in Figure 15. The graph is not linear between ideal and real value of the DAC output voltage. The ideal value of the DAC output voltage has deviation value 1.25. Testing is done by measuring real value of the DAC output voltage. Its ideal value is calculated using equation:

$$
V_{D A C \text { ideal }}=\left(\frac{\text { duty cycle }}{1023} 20\right)-10
$$

This output voltage is ranging from $-10 \mathrm{~V}$ to $+10 \mathrm{~V}$ and set into 0 to $5 \mathrm{~V}$ by the signal conditioning as power input of ATmega8 microcontroller. From Table 2, it can be seen the error percentage is about $1 \%$ of signal coverage needed by the thyristor driver ranging from $-6.67 \mathrm{~V}$ to $6.67 \mathrm{~V}$. In angular size, the firing angle of the thyristor is set ranging from $30^{\circ}$ to $150^{\circ}$ that is shown by the data with grey background of Table 2 .

There are three action steps in every cycle of control sampling time: analog to digital conversion process, arithmetical calculation for control, and PWM formation. Analog to digital conversion process takes 122 us. With its advanced Reduced Instruction Set Computing (RISC) architecture feature, ATmega 8 microcontroller is able to execute most of 131 power instructions with single clock cycle. Hence, the computation rate for arithmetical process can be ignored if compared to the process of ADC input reading. Furthermore, ATmega 8 microcontroller is equipped with on-chip 2-cycle multiplier. PWM formation takes time less significant if compared to conversion process of ADC. Therefore, the overall process time in every cycle of control sampling time is about 150 us if assumed that arithmetical calculation time and PWM formation are estimated 28 us. The amount of time is less than $10 \mathrm{~ms}$ of the cycle of control sampling time so that the computation rate of ATmega 8 is adequate.

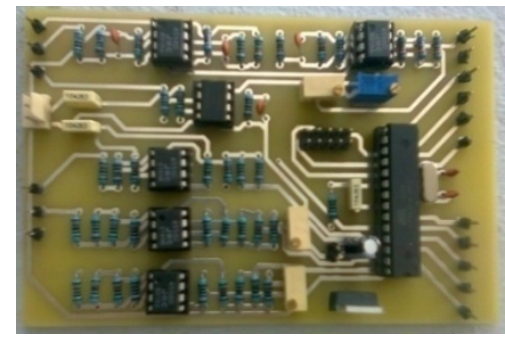

Figure 13. Digital AVR

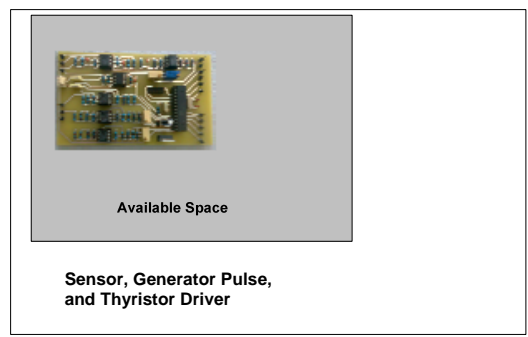

Figure 14. Comparison between digital and analog AVR

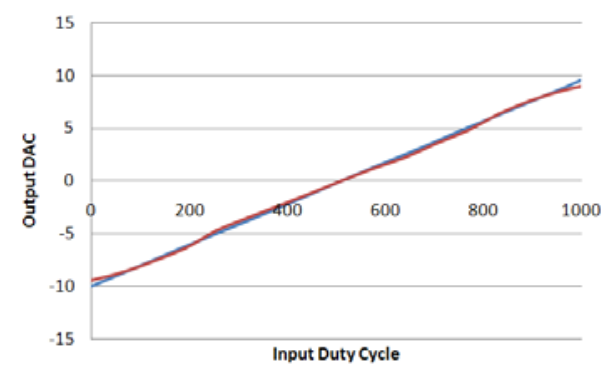

Figure 15. The output of DAC 


\begin{tabular}{lrc}
\multicolumn{1}{c}{ Table 1. Analog and Digital AVR Components } \\
\hline \multicolumn{1}{c}{ Components } & Analog & Digital \\
\hline Counter & 2 & - \\
DAC 8 bit & 1 & - \\
Dioda & 76 & - \\
Inverter & 8 & - \\
Capacitor & 31 & 8 \\
Nand 2 input & 4 & - \\
Nand 4 input & 2 & - \\
Nor 2 input & 1 & - \\
Nor 4 input & 1 & - \\
Op amp & 14 & 6 \\
Relay & 5 & - \\
Resistor & 202 & 41 \\
Transistor & 2 & - \\
VR & 38 & 4 \\
Zener & 11 & - \\
Microcontroller & - & 1 \\
Crystal & - & 1 \\
\hline
\end{tabular}

Table 2. DAC Output Voltage

\begin{tabular}{cccc}
\hline Duty Cycle & Ideal & Real & Error (\%) \\
\hline 0 & -10.00 & -9.39 & -3.05 \\
63 & -8.75 & -8.71 & -0.20 \\
127 & -7.50 & -7.67 & 0.85 \\
191 & -6.25 & -6.35 & 0.50 \\
255 & -5.00 & -4.70 & -1.50 \\
319 & -3.75 & -3.49 & -1.30 \\
383 & -2.50 & -2.33 & -0.87 \\
447 & -1.25 & -1.17 & -0.42 \\
511 & 0.00 & 0.00 & 0.00 \\
575 & 1.25 & 1.15 & 0.52 \\
639 & 2.50 & 2.23 & 1.37 \\
703 & 3.75 & 3.49 & 1.33 \\
767 & 5.00 & 4.77 & 1.15 \\
831 & 6.25 & 6.33 & -0.40 \\
895 & 7.50 & 7.56 & -0.30 \\
959 & 8.75 & 8.54 & 1.05 \\
1023 & 10.00 & 9.21 & 3.95 \\
\hline
\end{tabular}

Figure 16 to Figure 17 show the experimental result of digital AVR that appropriate to the simulation result shown in Figure 11 and Figure 12. However, there are some distortion ripples exist in the waveform. Therefore it is needed to be investigated the used filter for future research due to the remaining PWM ripples. It is also needed to be compared by using external non PWM DAC, e.g. DAC 0808. The formation of analog signal wave in DAC 0808 is not derived from the square wave as in PWM-type DAC hence ripples are not generated in the analog signal output. With no DAC ripples, the ripples in the terminal voltage is estimated significantly reduced.

Another approach is by using Digital Signal Processing to build an adjustable excitation device [21]. Carrier frequency gives impact to the output waveform that the higher the PWM carrier frequency results in the smoother output waveform while greater error of actual stator phase voltage will be occured. This is because the higher the PWM carrier frequency, the smaller the amount exciter current pulse. Thus the stator voltage harmonic content would be smaller. The $\mathrm{C}$ programming language is also used to implement several tasks in terms of estimation, fault recognition, and measurement of plant outputs [22]. This method allows a smooth startup of the adaptive controller and eliminates induced transient oscillations. It allows an initial period for the parameters to obtain reasonable levels, and then to ramp up the output of the self-tuning regulator gradually. Thus, it allows the parameters to converge smoothly, whilst providing a stable output. Areas of concern include oscillations in terminal voltage, excessive frequency or voltage fluctuations, or significant deviations from the set point. External faults on the system may give rise to the behaviour. The presence of such phenomena can lead to invalid models being generated under highly non linear conditions. The computational performance requirements to carry out the measurement and control would be excessive and infeasible in realtime if the programs were entirely sequential.

The proposed digital AVR replaces the analog AVR by using embedded system that is implemented in ATmega 8 microcontroller. The use of digital component makes maintenance easier. This 
happens since digital component is compatible with other components of the controller, not to mention its availability in local market. The space that is needed by the digital AVR is also diminished and its power consumption is less than the analog AVR.

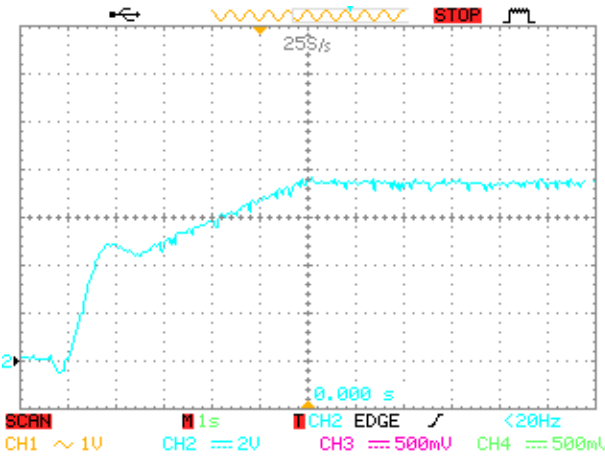

Figure 16. Response with ramp reference using filter

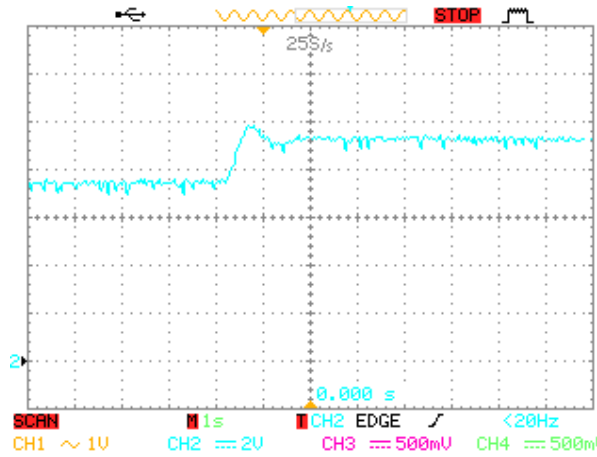

Figure 17. Step response testing using second- order filter

\section{CONCLUSION}

In this research, the digital AVR has been designed according to the analog AVR that has been applied in industry. The result shows that the designed digital AVR can reduce the size and power consumption of the analog AVR. Moreover, the performance of digital AVR also meets the limit of computation time. The compatibility of digital component with other controller parts and its availability in local market make the maintenance of AVR easier. In the next research, integration with the other AVR module, i.e. FARMON, thyristor driver, and sensor should be done before the AVR be tested in the hydro power plant.

\section{REFERENCES}

[1] Kundur P. Power System Stability and Control. McGraw Hill. New York. 1994.

[2] Machowski J, Bialek J W, Bumby J R. Power System Dynamics: Stability and Control. $2^{\text {nd }}$ Edition. John Wiley \& Sons. New Delhi. 2008.

[3] The History of Basler Electric [Internet]. 2012 [cited 2012 December 13]. Available from: http://www.basler.com/html/comhis.htm.

[4] Muqorobin A. Peningkatan Kemampuan Adopsi Teknologi Digital untuk Rancang Bangun AVR Digital Berbasis AVR Analog Mitra Industri untuk Pembangkit Listrik Tenaga Air Skala 6 MW. Laporan Kemajuan Tahap II Program Insentif Peningkatan Kapasitas Iptek Sistem Produksi. Bandung. 2010.

[5] Rijanto E, Muqorobin A. Rancang Bangun Modul Pengkondisi Sinyal dan Antar Muka untuk Kontroler Tegangan Digital Pada Pembangkit Listrik Tenaga Air (PLTA). Jurnal Ketenagalistrikan dan Energi Terbarukan. 2011; 10(1): 61-74.

[6] Schaefer RC, Kim K. Digital Excitation System Provides Enhanced Tuning Over Analog Systems. IEEE Pulp and Paper Industry Technical Conference. 2000: 84-91.

[7] Brimsek M, Kim K, Rao P, Schaefer RC. Feature Enhancements in New Digital Excitiation System Speeds Performance Testing [Internet]. 2006. Available from: http://www.basler.com/downloads/ EPRI_Tuning.pdf.

[8] Barakat A, Tnani S, Champenois G, Mouni E. A New Approach for Synchronous Generator Terminal Voltage Control - Comparison with a Standard Industrial Controller. Electric Power Systems Research. 2011; 81: 15921601.

[9] Su CT, Hwung HR, Lii GR. Fuzzy Logic Based Voltage Control for a Synchronous Generator. Electric Power Systems Research. 1997; 41: 225-231.

[10] Sisworahardjo NS, El-Sharkh MY, Alam MS. Neural Network Controller for Microturbine Power Plants. Electric Power Systems Research. 2008; 78: 1378-1384.

[11] Kim K, Schaefer RC. Tuning a PID Controller for a Digital Excitation Control System. IEEE Transactions on Industry Application. 2005; 41(2): 485-492.

[12] Bhatt VK, Bhongade S. Design of PID Controller in Automatic Voltage Regulator (AVR) System Using PSO Technique. International Journal of Engineering Research and Applications (IJERA). 2013; 3(4): 1480-1485.

[13] Zhou G, Ya T, Zhao S. A Three-Phase AC-Voltage Regulator System. TELKOMNIKA Indonesian Journal of Electrical Engineering. 2014; 12(5): 3501-3508.

[14] Ahmed T S, Sao S, Anjaneyulu KSR. Microcontroller Based Stator Resistance Determination of Induction Motor on Temperature Variations. International Journal of Power Electronics and Drive System. 2014; 4(3): 356-362. 
[15] Haque MM, Hossain MK, Ali MM, Sheikh MRI. Microcontroller Based Single Phase Digital Prepaid Energy Meter for Improved Metering and Billing System. International Journal of Power Electronics and Drive System (IJPEDS). 2011; 1(2): 139-147.

[16] Automatic Voltage Regulator for Synchronous Generator (Thyristor Direct Exciting System) Instruction Manual. Fuji Electric co ltd. 1987.

[17] Ogata K. Modern Control Engineering. $4^{\text {th }}$ Edition. Prentice Hall. New Jersey. 2002.

[18] Vahid F, Givargis T. Embedded System Design: a Unified Hardware / Software Introduction. John Wiley \& Sons. New Jersey. 2002.

[19] Atmel. ATmega8: 8-bit Atmel with 8 Kbytes in-system Programmable Flash [Internet]. 2012 [cited 2012 December 13]. Available from: http://www.atmel.com/images/atmel-2486-8-bit-avr-microcontroller-atmega8_l_datasheet.pdf.

[20] Kim K, Rao P, Burnworth J. Self-Tuning of the PID Controller for a Digital Excitation Control System. IEEE Transactions on Industry Application. 2010; 46(4): 1518-1524.

[21] Xiang-yu G, Yu-lin Z, Yan F, Yu-juan Z, Shuai S. Research on DSP-Based Automatic Excitation Regulator in Small Rural Hydropower Station. Journal of Northeast Agricultural University. 2013; 20: 65-69.

[22] Flynn D, Hogg BW, Swidenbank E, Zachariah KJ. Expert Control of a Self-Tuning Automatic Voltage Regulator. Control Engineering Practice. 1995; 3: 1571-1579. 